\title{
Quad Band Handset Antenna for LTE MIMO and WLAN Application
}

\author{
H. S. Wong, S. Kibria, M. T. Islam, J. S. Mandeep, and N. Misran \\ Institute of Space Science (ANGKASA), Universiti Kebangsaan Malaysia (UKM), 43600 Bangi, Selangor Darul Ehsan, Malaysia \\ Correspondence should be addressed to H. S. Wong; hueyshin_86@yahoo.com
}

Received 17 November 2013; Accepted 11 January 2014; Published 17 April 2014

Academic Editor: Rezaul Azim

Copyright (C) 2014 H. S. Wong et al. This is an open access article distributed under the Creative Commons Attribution License, which permits unrestricted use, distribution, and reproduction in any medium, provided the original work is properly cited.

\begin{abstract}
A compact quad band antenna for long-term evolution (LTE) MIMO and WLAN application in the handset is presented in this paper. The proposed antenna comprises two symmetrical quarter wavelength radiating strips and a slotted ground plane. On the ground plane, a T-shaped slot is cut from the bottom. Two symmetrical P-shaped slots are etched at both sides of the ground plane. The radiating strips and slots generate a lower resonant at $780 \mathrm{MHz}$ and an upper resonant at $2.350 \mathrm{GHz}$ to cover LTE $700 \mathrm{Band}$ 14, LTE 2300, 2.4 GHz WLAN, and LTE 2500. A novel isolation technique by placing a rectangular patch between the radiating strips is presented. The rectangular patch creates a dedicated current path for each radiating strip. The proposed antenna has high isolation of less than $-18 \mathrm{dBi}$ at LTE $2300,2.4 \mathrm{GHz}$ WLAN, and LTE 2500 band.
\end{abstract}

\section{Introduction}

In this information age, the usage of mobile handsets has become more important to transfer information across the globe instantly. With the growing usage of the mobile handset to transfer information, the development of handset antenna to support all the features of the mobile handset has become crucial. Due to the miniaturization of handsets, it is desirable for the antenna to be of compact profile and simple structure [1]. A low profile planar structure antenna that has wide bandwidth is proposed in [2]. In [3], a single-layer substrate antenna fed by a coplanar waveguide (CPW) is proposed. The single element antenna proposed in [4] is compact and occupies a small volume. Slot antennas are popular due to its low profile and planar structure. Many proposed antennas achieve wide bandwidth by cutting slots in the ground plane $[5,6]$.

Over the last few years, many countries have adopted the long-term evolution (LTE) standard. The reason of the rapid growth of the LTE standard is because of its ability to fulfil the high demand of mobile data traffic. LTE can deliver data at the rates of at least $100 \mathrm{Mb} / \mathrm{s}$ downlink and $50 \mathrm{Mb} / \mathrm{s}$ uplink [7]. Multiple input and multiple output (MIMO) technology is used to enhance the channel capacity of the LTE communication system. Antenna arrays are usually used in MIMO communication systems. The most important factor of a good MIMO antenna is low mutual coupling between the antenna arrays. Good isolation between multiple antennas is more difficult to achieve with the requirement of the handset antenna size being as compact as possible. One of the techniques to achieve high isolation between two folded monopole antennas is by adding a vertical ground wall as shown in [8]. In [9], the mutual coupling between multiple antenna elements is reduced by cutting split-ring slots inside two reversely connected rectangular patches.

The allocation of the $700 \mathrm{MHz}$ band for LTE 700 makes the design of a compact MIMO antenna for LTE 700 application more challenging. This is because the quarter wavelength of $700 \mathrm{MHz}$ is much bigger than the size of a typical handset. LTE 700, LTE 2300, and LTE 2500 are the most commonly used LTE bands around the world especially in Europe, United States, and Asia regions. The development of an LTE MIMO antenna that can cover all three bands is very much in demand. Many LTE antennas [10-12] have been proposed, but most of these antennas either cannot be used for MIMO applications or cannot cover LTE700/2300/2500. In [13], the antenna can operate in LTE 700, LTE 2300, and LTE 2500 but does not have MIMO characteristics. The antenna proposed 

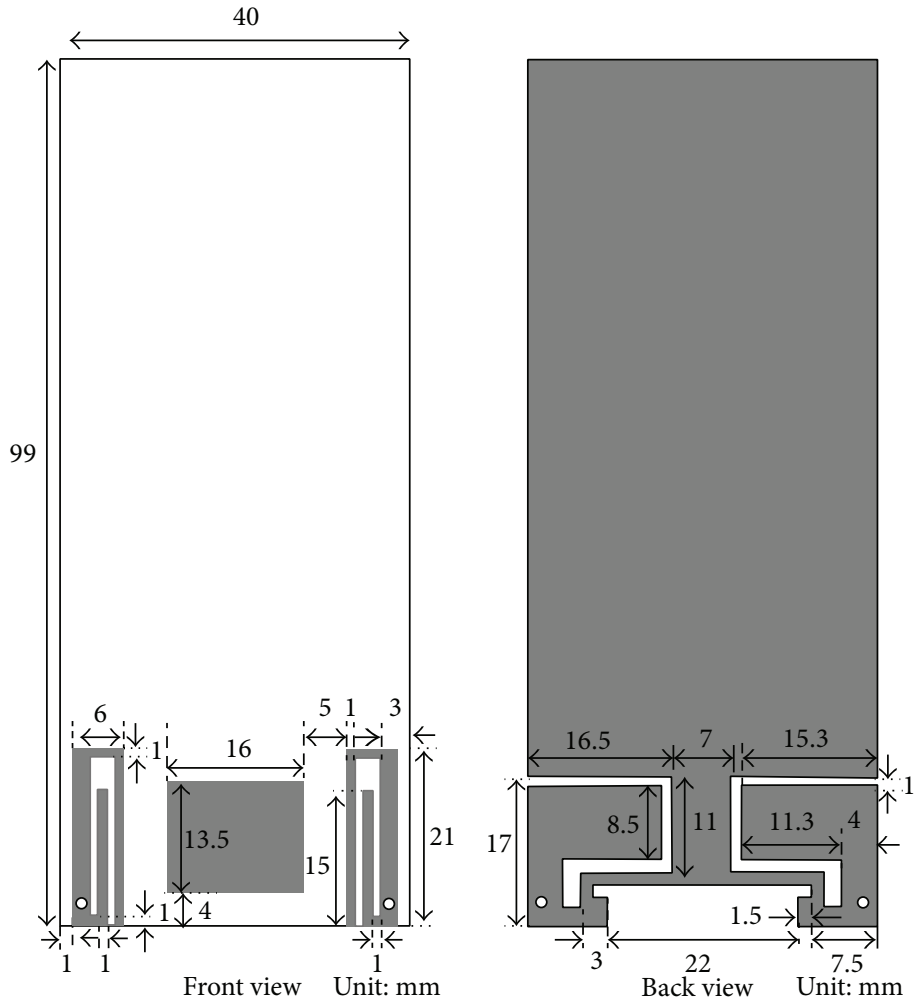

FIGURE 1: Front and back view of structure and dimension of proposed antenna.

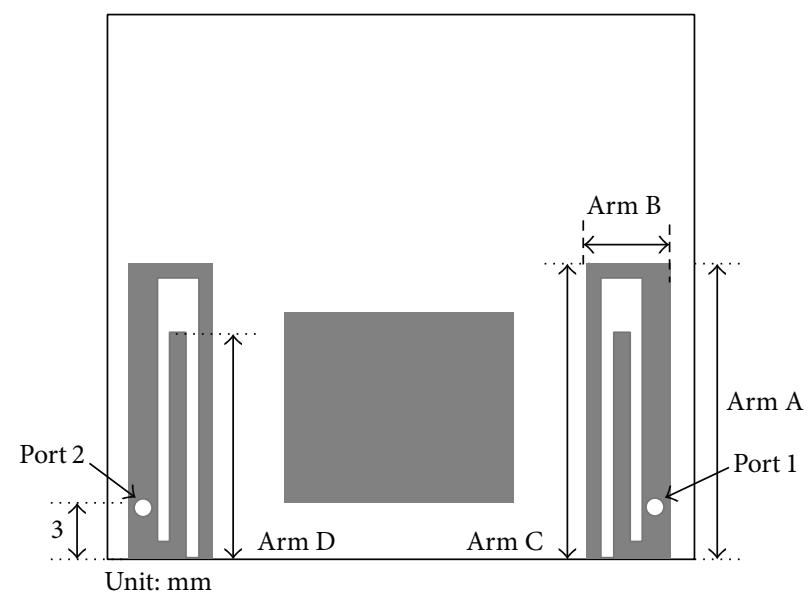

FIGURE 2: Detailed front view of structure of proposed antenna.

in $[14,15]$ could be used for LTE 700 MIMO application but could not operate in LTE 2300 and LTE 2500 bands. In order to achieve LTE MIMO operation in the LTE700/2300/2500 bands, the common approach is to use an auxiliary antenna such as in [16]. These designs have complex configuration and usually have a large size. For example, a MIMO folded monopole antenna with the size of $50 \mathrm{~mm} \times 20 \mathrm{~mm}^{2}$ for LTE 700, LTE 2300, and LTE 2500 applications is presented in [17].

In order to cover LTE 2300 and LTE 2500, techniques to widen the upper bandwidth must be taken into consideration in the antenna design. There are many broadbanding techniques proposed such as using a circular ring-shaped radiator [18]. The antenna proposed in [19] is compact sized and wideband. The compact size of the antenna is achieved by the circular ring-shaped structure. Antenna design optimization technique such as particle swarm optimization is effective in improving the bandwidth such as shown in [20].

In this paper, a MIMO antenna that covers LTE 700, LTE $2300,2.4 \mathrm{GHz}$ WLAN, and LTE 2500 is presented. By folding the quarter wavelength radiating strips, the size of the antenna is reduced significantly. The novel isolating 


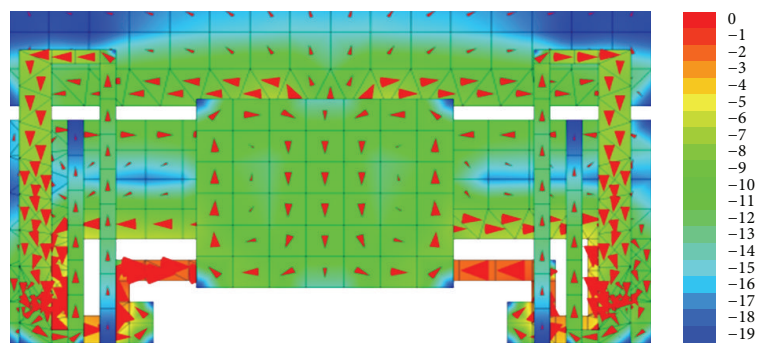

(a)

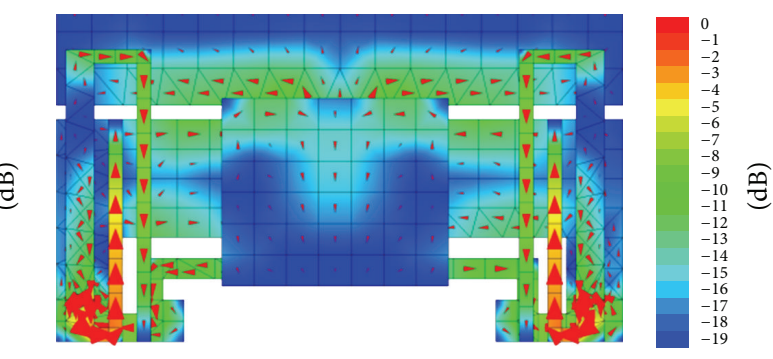

(b)

Figure 3: (a) Surface current distribution at $780 \mathrm{MHz}$ of the front side of the antenna. (b) Surface current distribution at $2.350 \mathrm{GHz}$ of the front side of the antenna.

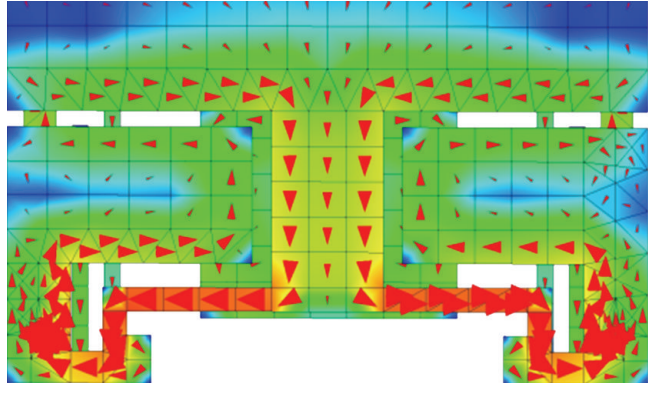

(a)

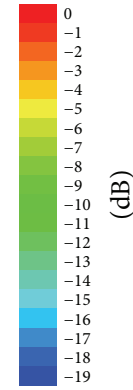

$-19$

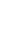

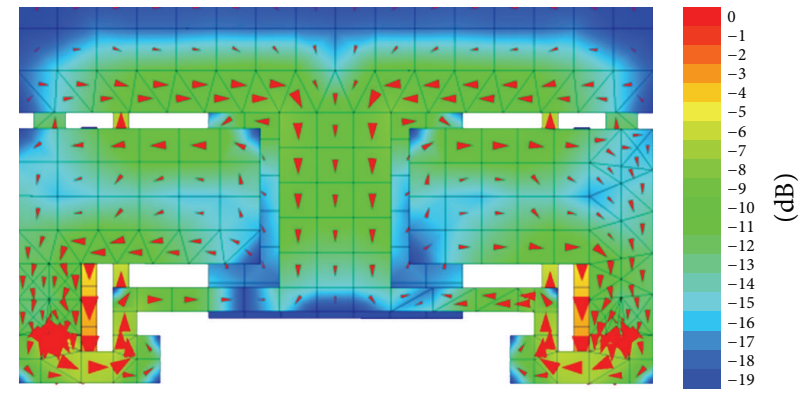

(b)

FIGURE 4: (a) Surface current distribution at $780 \mathrm{MHz}$ of the back side of the antenna. (b) Surface current distribution at $2.350 \mathrm{GHz}$ of the back side of the antenna.

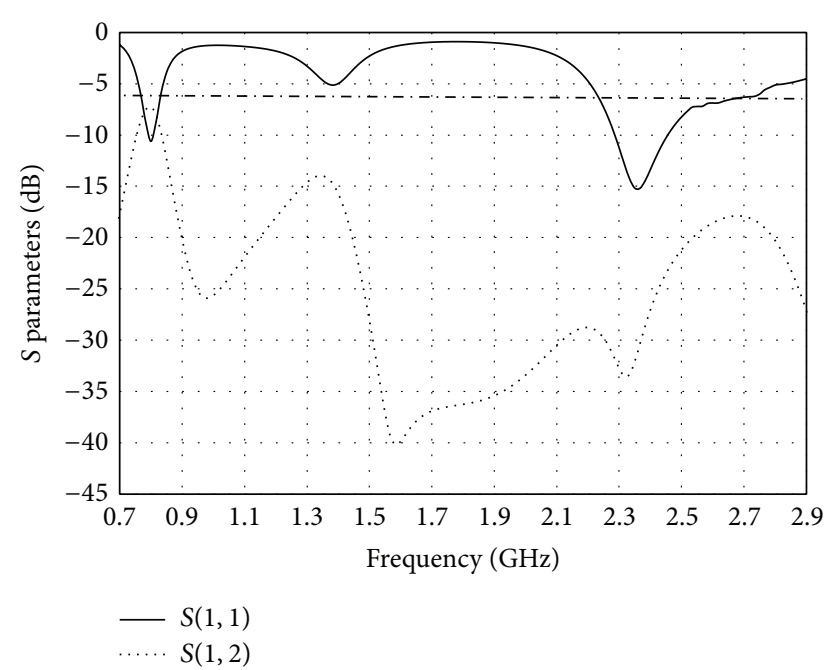

Figure 5: $S_{11}$ and $S_{12}(\mathrm{~dB})$ for the proposed antenna.

patch placed between the radiating strips reduces the mutual coupling between the two ports for over than $18 \mathrm{~dB}$ at the upper band. The proposed antenna in this paper has a much simpler structure and smaller size compared to $[16,17]$. The following section of this paper discusses the antenna design in detail. The results and the parametric study done on the proposed antenna are presented in the next section. The conclusion is provided in the last section.

\section{Antenna Design}

The proposed LTE MIMO antenna occupies a small area of $21 \times 40 \mathrm{~mm}^{2}$ on a total printed circuit board (PCB) size of $99 \times 40 \mathrm{~mm}^{2}$ as shown in Figure 1. It is printed on a $1.6 \mathrm{~mm}$ thick FR4 substrate with dielectric constant of 4.6 and loss tangent of 0.02 . On the front side of the antenna, two symmetrical radiating strips are placed at both sides of a rectangular patch. Each radiating strip is connected to the ground plane by a shorting pin with a distance of $3 \mathrm{~mm}$ from the bottom of the antenna. It is fed by a $50 \mathrm{ohm}$ SMA coaxial probe. The radiating strips can be separated into four arms: A, B, C, and D as depicted in Figure 2. Arms A, B, and C resonate at the lower band while Arm $D$ resonates at the upper band. The total length of the three arms (A, B, and C) of the radiating strips is $48 \mathrm{~mm}$ which is about quarter wavelength of $780 \mathrm{MHz}$. Arm D has a length of $15 \mathrm{~mm}$ that is around quarter wavelength of $2.350 \mathrm{GHz}$. The current distribution of the front view of the proposed antenna at $780 \mathrm{MHz}$ and $2.350 \mathrm{GHz}$ is illustrated in Figure 3. At $780 \mathrm{MHz}$, the current distribution is concentrated at Arms A, B, and C of the radiating strip as shown in Figure 3(a). On the other hand, a high concentration of current is observed at Arm D of the radiating strip at $2.350 \mathrm{GHz}$ as depicted in Figure 3(b). Two symmetrical P-shaped slots are etched on both sides of the ground plane and are coupled by the radiating strips. The P-shaped slots play a significant role to achieve the lower resonant at $780 \mathrm{MHz}$ and upper resonant at $2.350 \mathrm{GHz}$. In Figures 4(a) and 4(b), the current distribution of the back 


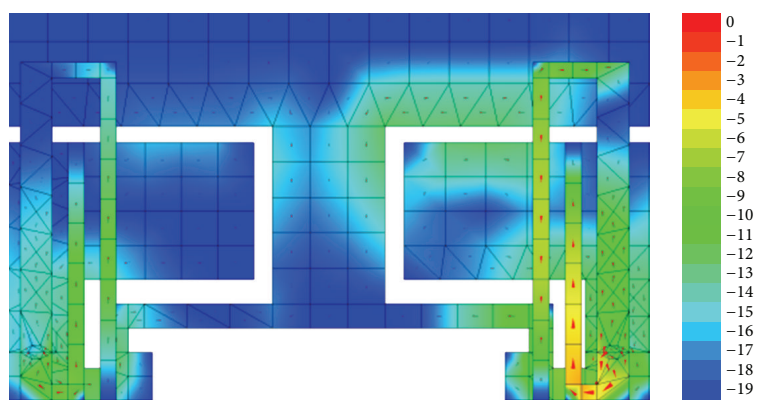

(a)

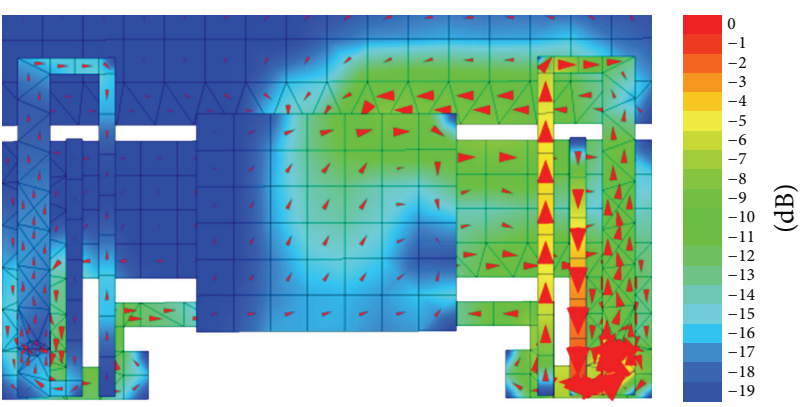

(b)

Figure 6: Front view of the antenna. Surface current distributions at $2.350 \mathrm{GHz}$ when Port 1 is excited. (a) Without the rectangular patch. (b) With the rectangular patch.

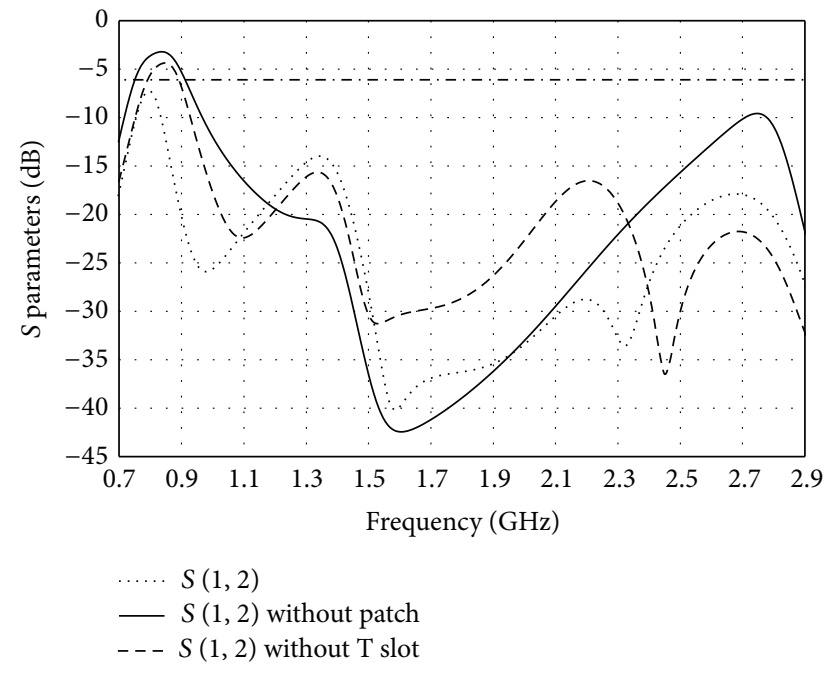

FIGURE 7: $S_{12}(\mathrm{~dB})$ with the patch and T-shaped slot; $S_{12}(\mathrm{~dB})$ without the patch and $S_{12}(\mathrm{~dB})$ without the T-shaped slot.

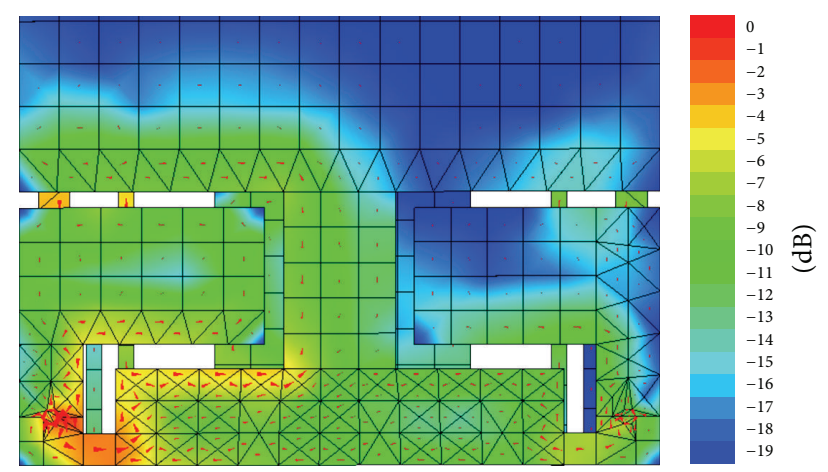

FIGURE 8: Back view of the antenna. Surface current distributions without the T-shaped slot at $780 \mathrm{MHz}$ when Port 1 is excited.

view of the proposed antenna at $780 \mathrm{MHz}$ and $2.350 \mathrm{GHz}$ is shown, respectively. It can be seen that the areas surrounding the P-shaped slots have very high concentration of current.

In order to improve the isolation of the proposed antenna, a rectangular patch is placed in between the two radiating strips. The purpose of this rectangular patch is to provide a dedicated current path for each radiating strip to flow. It can be seen in Figure 3 that the current flow follows two independent circular paths inside the rectangular patch. The current flowing from Port 1 follows the circular path on the right side of the rectangular patch and vice versa. Hence, the current waves from Port 1 will not flow to Port 2 which reduces the mutual coupling between the two ports. A Tshaped slot which is cut at the bottom of the ground plane acts as a parasitic element to further reduce the isolation at LTE 700 band. The two arms of the T-shaped slot limit the area current flow. Therefore, a very high concentration of current at left and right arms of the T-shaped slot can be observed in Figure 3(a). IE3D electromagnetic simulator tool is used to design and optimize the dimensions of the radiating line, rectangular patch, and slots.

\section{Result and Analysis}

In this section, the results of the proposed antenna and parametric study are presented. Figure 5 shows the S-parameter characteristics of the proposed LTE MIMO antenna satisfying VSWR 3:1 (-6 dB) for LTE 700 Band 14 (758 MHz$798 \mathrm{MHz}$ ), LTE $2300(2.305 \mathrm{GHz}$ to $2.400 \mathrm{GHz})$, LTE 2500 $(2.500 \mathrm{GHz}$ to $2.690 \mathrm{GHz})$, and $2.4 \mathrm{GHz}$ WLAN $(2.400 \mathrm{GHz}$ to $2.484 \mathrm{GHz}$ ). Due to the symmetrical characteristics of the proposed antenna, the $S$-parameter results for Port 2 are similar to Port 1 and are not shown in this paper. At the lower band, the $S_{11}$ covers from $753 \mathrm{MHz}$ to $800 \mathrm{MHz}$. On the other hand, the upper band has a wide bandwidth of $482 \mathrm{MHz}$ covering from $2.218 \mathrm{GHz}$ to $2.700 \mathrm{GHz}$. From Figure 5, it is shown that the proposed antenna has high isolation at $2.300 \mathrm{GHz}$ with $S_{12}$ of $-33.52 \mathrm{~dB}$. Overall, the $S_{12}$ at the upper band is less than $-18.00 \mathrm{~dB}$ whereas at the lower band the isolation is less than $-7.54 \mathrm{~dB}$.

To demonstrate the effects of the isolating rectangular patch, the current distribution at $2.350 \mathrm{GHz}$ with and without the rectangular patch is shown in Figure 6. It can be observed in Figure 6(a) that the current distribution at Port 2 radiating strip is quite high. In Figure 6(b), the current from Port 1 radiating strip flows in from the top and flows out to the right side of the of rectangular patch creating a loop. With 

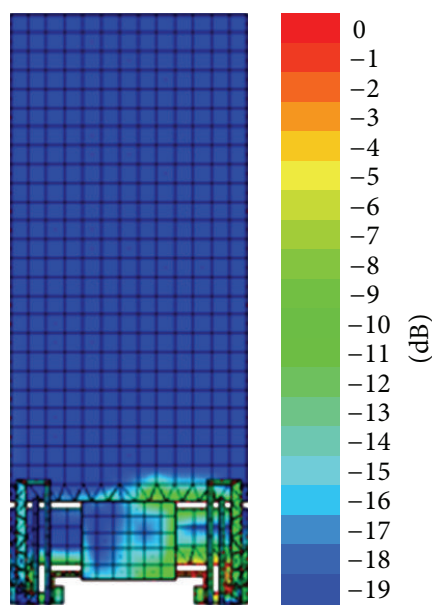

(a)
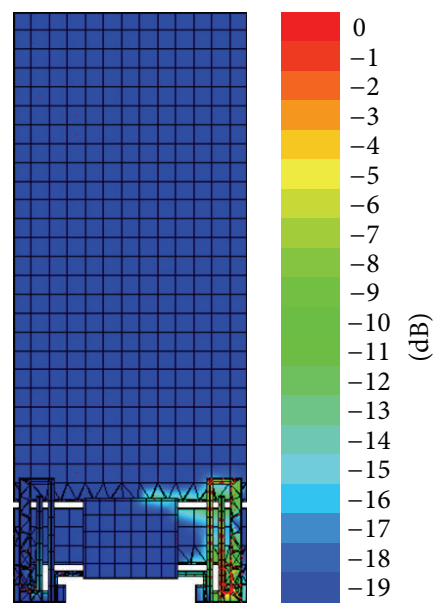

(c)

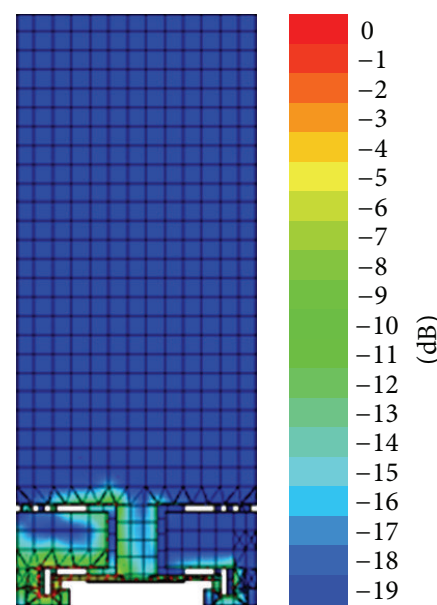

(b)

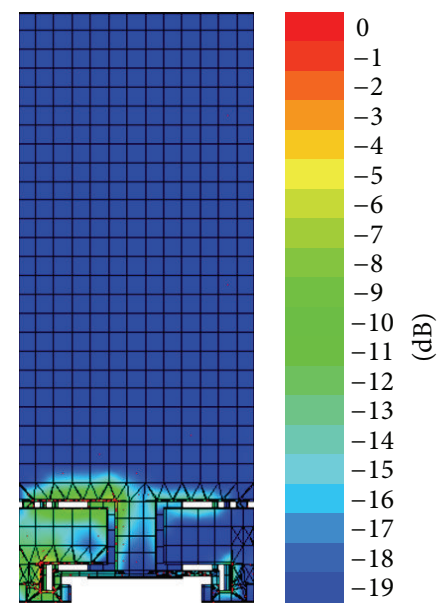

(d)

Figure 9: (a) Front view of surface current distributions at $780 \mathrm{MHz}$ when Port 1 is excited. (b) Back view of surface current distributions at $780 \mathrm{MHz}$ when Port 1 is excited. (c) Front view of surface current distributions at $2.350 \mathrm{GHz}$ when Port 1 is excited. (d) Back view of surface current distributions at $2.350 \mathrm{GHz}$ when Port 1 is excited.

the presence of the rectangular patch, the current flow follows a loop-shaped path. This phenomenon reduces the mutual coupling between the two radiating strips considerably. As shown in Figure 7, at $2.5 \mathrm{GHz}$, the $S_{12}$ without isolating patch is $-15.68 \mathrm{~dB}$ whereas the $S_{12}$ with isolating patch is reduced to $-20.59 \mathrm{~dB}$.

Figure 8 shows the current distribution without the Tshaped slot at $780 \mathrm{MHz}$. It can be seen that the current waves are dispersed to the entire area of the bottom ground plane. As shown in Figure 4, with the addition of the T-shaped slot, the currents are restricted to follow a narrow path on top of the T-shaped slot. As depicted in Figure 7, by adding the isolating patch and T-shaped slot, the $S_{12}$ at $780 \mathrm{MHz}$ has improved to $-7.54 \mathrm{~dB}$.

In Figures 9 and 10, the surface current distribution of each port is shown. It can be observed in Figure 9 that the current is concentrated at Port 1 when only Port 1 is fed. At Port 2, the current distribution is little. The current distribution when only Port 2 is excited is shown in Figure 10.
It can be found that the current distribution is concentrated at Port 2 whereas there is little current distribution at Port 1.

The radiation patterns at the frequency $2.350 \mathrm{GHz}$ are shown in Figure 11. It can be observed that the radiation pattern of Port 1 antenna is omnidirectional. Figure 12 shows the gain of the proposed antenna. The maximum gain of the antenna is $1.553 \mathrm{dBi}$ at $2.412 \mathrm{GHz}$.

\section{Conclusion}

A compact size LTE MIMO antenna is presented in this paper. The combination of the two quarter wavelength radiating elements with the $\mathrm{P}$-shaped slots on the ground plane generates two resonances at $780 \mathrm{MHz}$ and $2.350 \mathrm{GHz}$. A novel isolating patch is placed in between the two symmetrical radiating lines to improve the isolation at the upper band. To reduce the mutual coupling at the lower band, a T-shaped slot is cut from the bottom of the ground plane. The proposed 

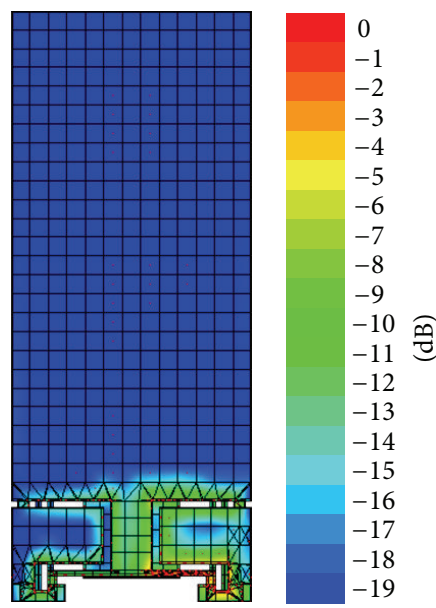

(a)

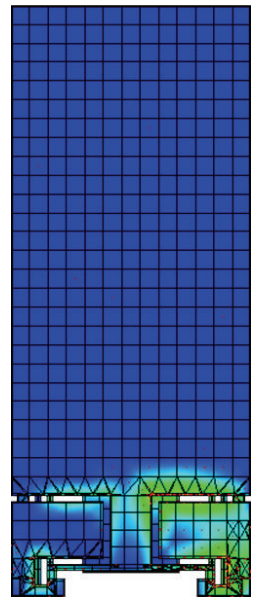

(c)

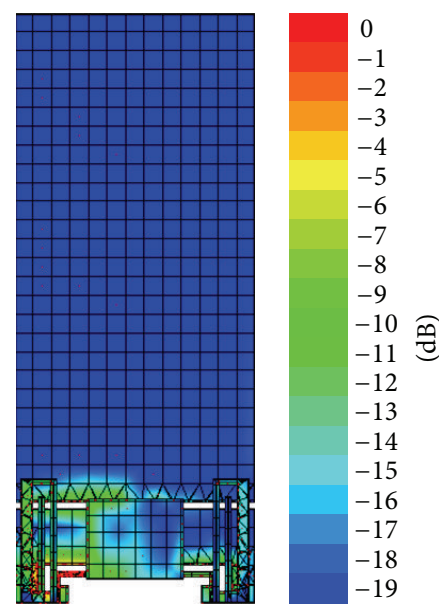

(b)

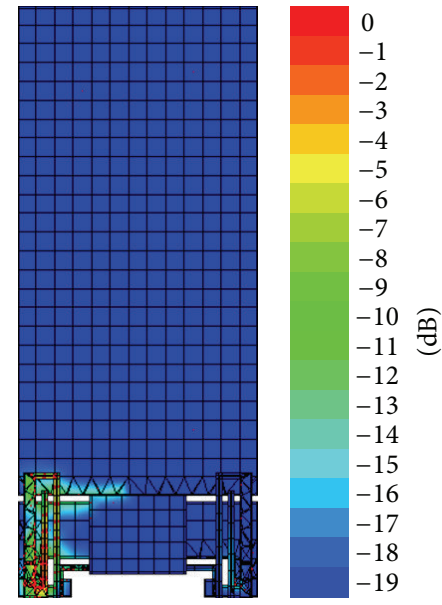

(d)

FIgURE 10: (a) Front view of surface current distributions at $780 \mathrm{MHz}$ when Port 2 is excited. (b) Back view of surface current distributions at $780 \mathrm{MHz}$ when Port 2 is excited. (c) Front view of surface current distributions at $2.350 \mathrm{GHz}$ when Port 2 is excited. (d) Back view of surface current distributions at $2.350 \mathrm{GHz}$ when Port 2 is excited.

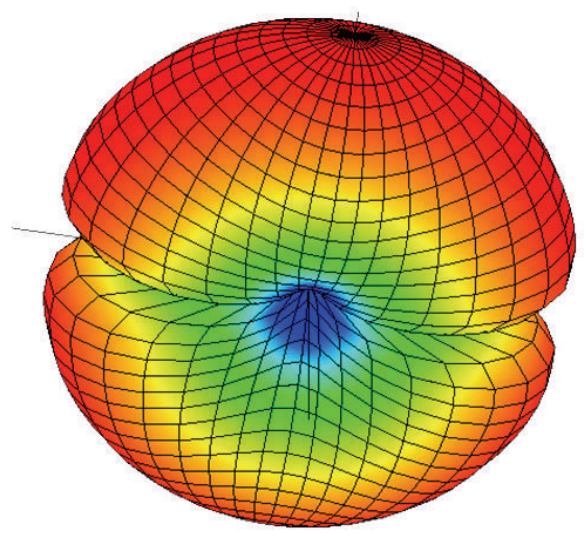

(a)

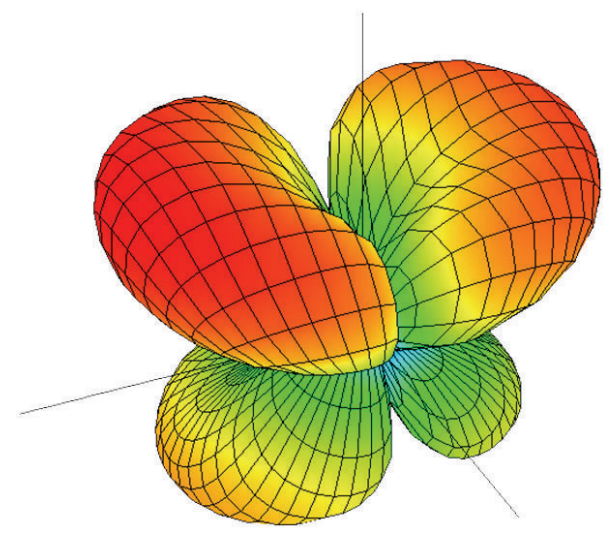

(b)

FIGURE 11: Radiation patterns of the proposed antenna at (a) $780 \mathrm{MHz}$ and (b) $2.350 \mathrm{GHz}$ plane. 


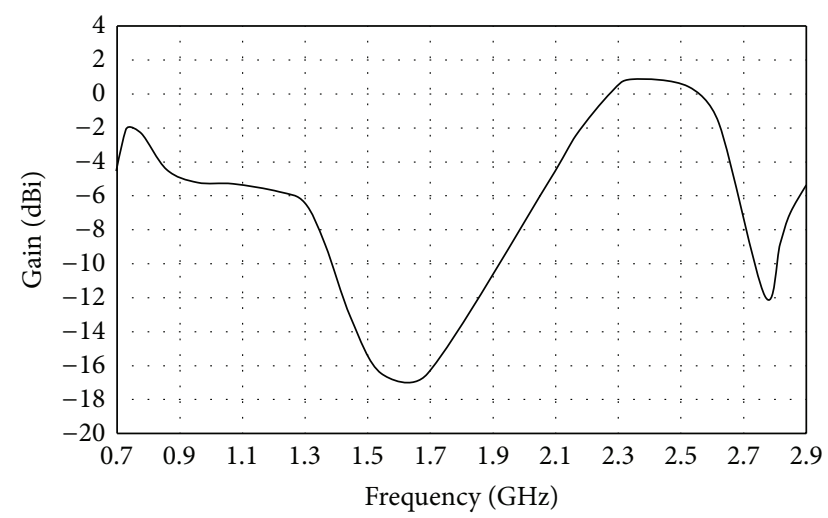

Figure 12: Total gain of the proposed antenna.

antenna has a small size, good isolation characteristics, and wide bandwidth. It is suitable to be used in handsets for LTE 700, LTE 2300, LTE 2500, and 2.4 GHz WLAN application.

\section{Conflict of Interests}

The authors declare that there is no conflict of interests regarding the publication of this paper.

\section{Acknowledgment}

The authors would like to thank the Ministry of Education, Malaysia, for sponsoring this work under ERGS Project (ERGS/1/2012/TK06/UKM/02/8).

\section{References}

[1] C. J. Reddy and G. Gampala, Antenna Design Considerations for LTE Mobile Applications, IEEE Long Island Section, 2011.

[2] R. Azim, M. T. Islam, and N. Misran, "Printed planar antenna for wideband applications," Journal of Infrared, Millimeter, and Terahertz Waves, vol. 31, no. 8, pp. 969-978, 2010.

[3] M. T. Islam, A. T. Mobashsher, and N. Misran, "Coplanar waveguide fed printed antenna with compact size for broadband wireless applications," Journal of Infrared, Millimeter, and Terahertz Waves, vol. 31, no. 12, pp. 1427-1437, 2010.

[4] Q. Rao and D. Wang, "A compact dual-port diversity antenna for long-term evolution handheld devices," IEEE Transactions on Vehicular Technology, vol. 59, no. 3, pp. 1319-1329, 2010.

[5] R. Azim, M. T. Islam, N. Misran, and A. T. Mobashsher, "Compact UWB planar antenna for broadband applications," Informacije MIDEM, vol. 41, no. 1, pp. 37-40, 2011.

[6] R. Azim, A. T. Mobashsher, and M. T. Islam, "UWB antenna with notched band at $5.5 \mathrm{GHz}$," IET Electronics Letters, vol. 49, no. 15, pp. 922-924, 2013.

[7] E. Dahlman, S. Parkwall, and J. Skold, 4G: LTE/LTE-Advanced for Mobile Broadband, Academic Press, Oxford, UK, 2011.

[8] K. Chung and J. H. Yoon, "Integrated MIMO antenna with high isolation characteristic," Electronics Letters, vol. 43, no. 4, pp. 199-201, 2007.

[9] M. S. Alam, M. T. Islam, and N. Misran, "A novel compact split ring slotted electromagnetic bandgap structure for microstrip patch antenna performance enhancement," Progress in Electromagnetics Research, vol. 130, pp. 389-409, 2012.

[10] C. Q. Lei, Y. L. Ban, J. H. Chen, and J. L. W. Li, "Smallsize slot antenna for seven-band LTE/WWAN mobile phone operation," in Proceedings of the IEEE International Workshop on Electromagnetics; Applications and Student Innovation (iWEM '12), pp. 1-2, Chengdu, China, 2012.

[11] X. Zhao, Y. Lee, and J. Choi, "Design of a compact MIMO antenna using coupled feed for LTE mobile applications," International Journal of Antennas and Propagation, vol. 2013, Article ID 837643, 8 pages, 2013.

[12] C. H. Ku, H. W. Liu, and Y. X. Ding, "Design of planar coupledfed monopole antenna for eight-band LTE/WWAN mobile handset application," Progress in Electromagnetics Research C, vol. 33, pp. 185-198, 2012.

[13] Y. L. Ban, J. H. Chen, S. Yang, J. L. W. Li, and Y. J. Wu, "Lowprofile printed octa-band LTE/WWAN mobile phone antenna using embedded parallel resonant structure," IEEE Transactions on Antennas and Propagation, vol. 61, no. 7, pp. 3889-3894, 2013.

[14] G. Park, M. Kim, T. Yang, J. Byun, and A. S. Kim, “The compact quad-band mobile handset antenna for the LTE700 MIMO application," in Proceedings of the IEEE International Symposium on Antennas and Propagation, pp. 1-4, Charleston, SC, USA, June 2009.

[15] B. Mun, F. J. Harackiewicz, B. Kim et al., "New configuration of handset MIMO antenna for LTE 700 band applications," International Journal of Antennas and Propagation, vol. 2013, Article ID 850489, 6 pages, 2013.

[16] T.-W. Kang, K.-L. Wong, and M.-F. Tu, "Internal handset antenna array for LTE/WWAN and LTE MIMO operations," in Proceedings of the 5th European Conference on Antennas and Propagation (EUCAP '11), pp. 557-560, Rome, Italy, April 2011.

[17] S. H. Lee, C. Y. Yang, and W. G. Yang, "High isolation MIMO antenna design by using ground slits for mobile handset," in Proceedings of the Progress in Electromagnetics Research Symposium, pp. 589-593, Moscow, Russia, 2012.

[18] R. Azim, M. T. Islam, J. S. Mandeep, and A. T. Mobashsher, "A planar circular ring ultra-wideband antenna with dual bandnotched characteristics," Journal of Electromagnetic Waves and Applications, vol. 26, no. 14-15, pp. 2022-2032, 2012.

[19] L. Liu, S. W. Cheung, R. Azim, and M. T. Islam, "A compact circular-ring antenna for ultra-wideband applications," Microwave and Optical Technology Letters, vol. 53, no. 10, pp. 2283-2288, 2011.

[20] M. T. Islam, M. Moniruzzaman, N. Misran, and M. N. Shakib, "Curve fitting based particle swarm optimization for uwb patch antenna," Journal of Electromagnetic Waves and Applications, vol. 23, no. 17-18, pp. 2421-2432, 2009. 

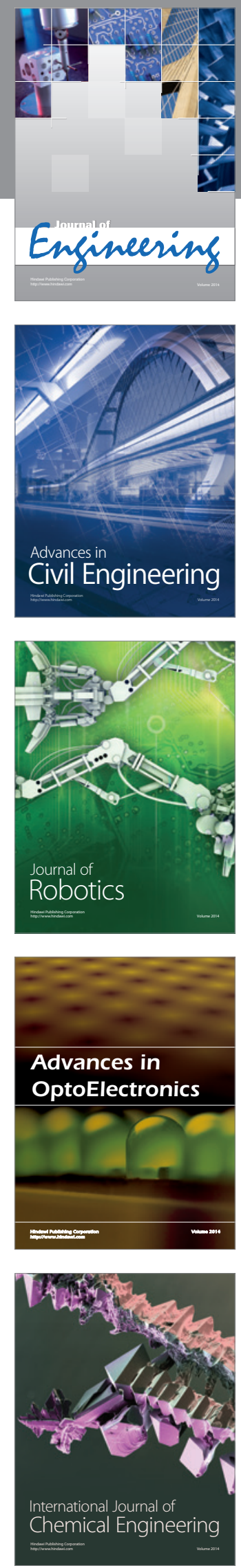

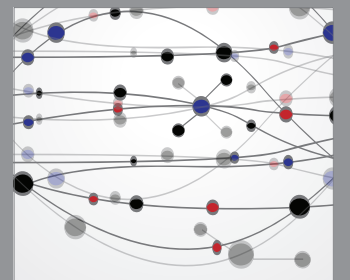

The Scientific World Journal
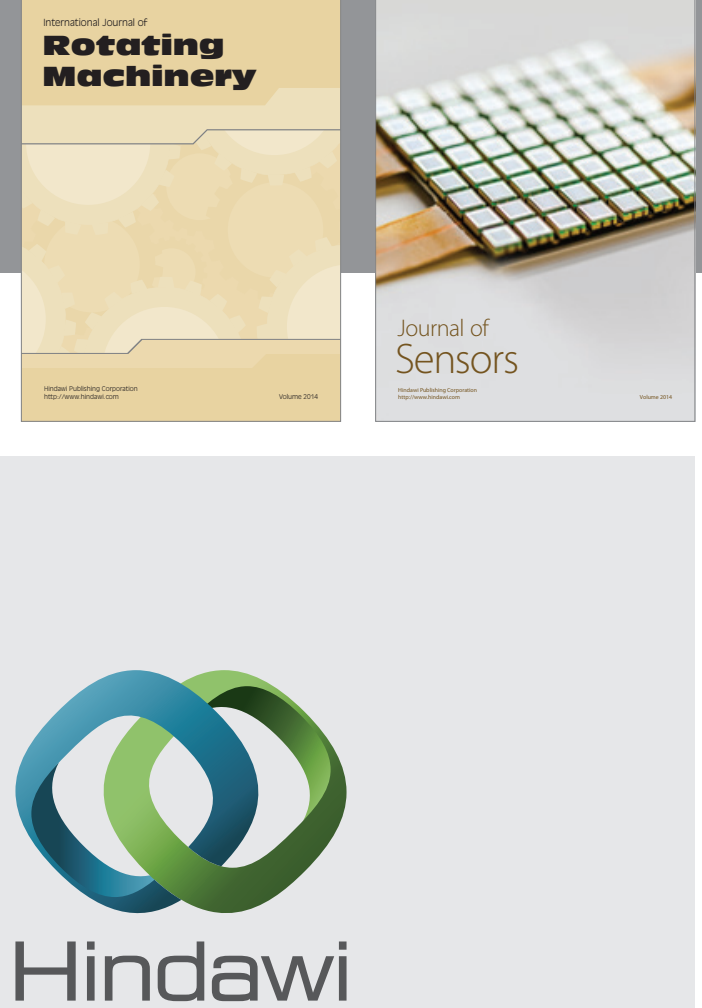

Submit your manuscripts at http://www.hindawi.com
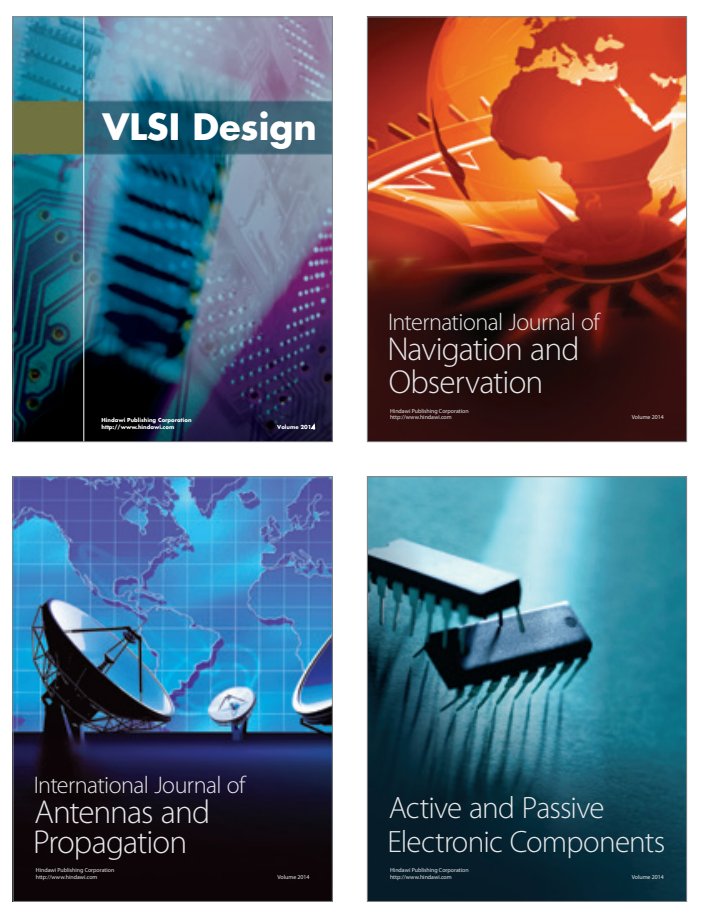
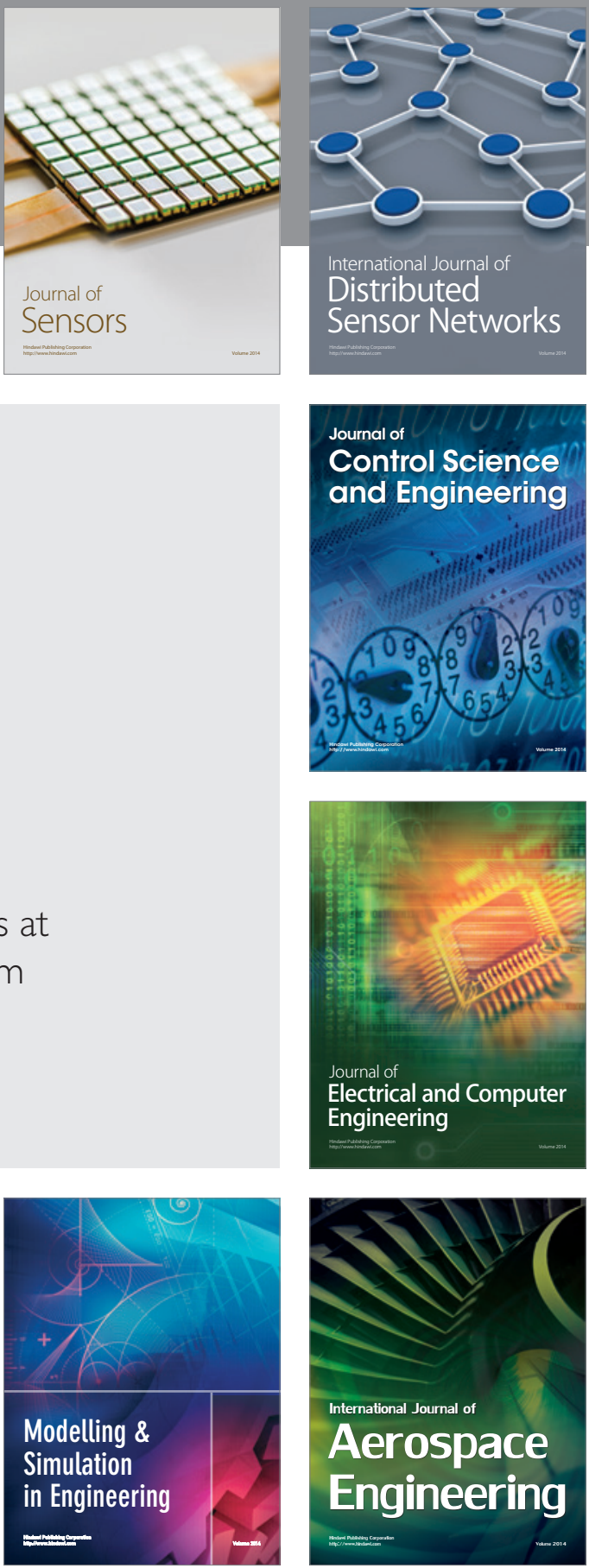

Journal of

Control Science

and Engineering
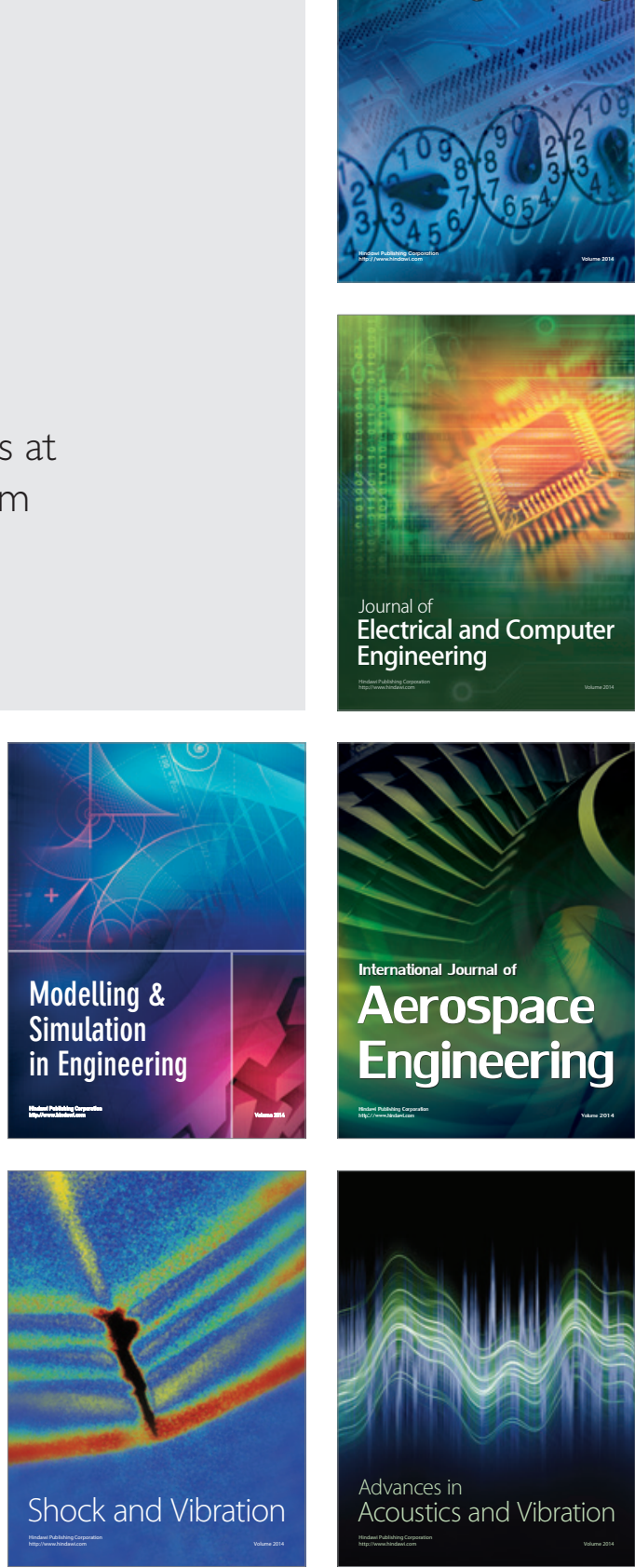